\title{
Science Fiction as an Entry Point for Ethical Frameworks in Engineering and Computer Science Education
}

\section{Dr. Valerie H. Summet, Rollins College}

Dr. Valerie Summet is an Assistant Professor of Computer Science at Rollins College, a liberal-arts school located in Winter Park, FL. Her research interests include human-computer interaction and CS education. She earned a BS in Computer Science from Duke University and an MS and PhD in Computer Science from the Georgia Institute of Technology.

\section{Prof. Rebecca A Bates, Minnesota State University, Mankato}

Rebecca A. Bates received the Ph.D. degree in electrical engineering from the University of Washington. She also received the M.T.S. degree from Harvard Divinity School. She is currently Professor and Chair of the Department of Integrated Engineering program at Minnesota State University, Mankato, home of the Iron Range, Twin Cities and Bell Engineering programs. 


\title{
Science Fiction as an Entry Point for Ethical Frameworks in Engineering and Computer Science Education
}

\begin{abstract}
Preparing students for ethical challenges in the course of their job responsibilities has been recognized as a priority by many professional organizations such as ACM, ABET, IEEE, NSPE, and other professional engineering societies. However, there has been debate about how and from whom students should receive ethics instruction. Embedding ethics into a technical, content-driven course often leaves faculty feeling time-pressured or unequipped to deliver ethics instruction. In this paper, we present a series of science fiction readings and discussion questions as a practical way to tie technical content to an engaging narrative. These exercises are intended to be stand-alone modules for a single 50-75 minute class period and could lead to further instruction in ethics. We also present resources for self-study of ethical theories, tips for leading class discussions, and other short stories for further study.
\end{abstract}

\section{Introduction}

Virtually every professional organization for mathematicians, scientists, and engineers contains a code of ethics or a statement of ethical behavior. For example, ACM's code of ethics states, "Computing professionals' actions change the world. To act responsibly, they should reflect upon the wider impacts of their work, consistently supporting the public good" [1]. This statement makes it clear that a student cannot consider their work in a vacuum, and it also makes clear that a student must connect their work to the impacts of that work.

ABET accreditation guidelines for colleges and universities include a student outcome that students from an ABET accredited undergraduate program will have "an ability to recognize ethical and professional responsibilities in engineering situations" [2]. The merging of both professional responsibility and ethical responsibility shows that one is not sufficient without the other. A student cannot demonstrate professional responsibility unless they can also demonstrate ethical responsibility and vice versa. Like the ACM, the National Society of Professional Engineers makes it clear that professional competency and ethics cannot be separated from one another, stating in the preamble to their code of ethics, "the services provided by engineers require honesty, impartiality, fairness, and equity, and must be dedicated to the protection of the public health, safety, and welfare" [3].

This sampling of statements makes clear that ethical thought, word, and deed are expected from graduating students. However, studies have cast doubt on whether simple exposure to a 
professional code of ethics influences practitioner behavior when confronted with an ethical dilemma [4]. Thus, universities must bear the brunt of a more complete, initial education in ethics as it relates to specific content areas such as engineering or computer science. However, the implementation of ethics education has long been a source of debate within universities.

In the updated ASEE Code of Ethics (2020), engineering educators are called to "work to cultivate students' abilities to recognize ethical and professional responsibilities in engineering situations and make informed judgments, including consideration of the impact of engineering solutions in global, economic, environmental, and societal contexts" as well as to encourage students to "use their knowledge and skills for the enhancement betterment of human welfare" and "be aware of the environmental and social impact of their solutions need for sustainable development and social justice and how engineers can contribute to both" [5]. While there has been debate, it is clear that engineering educators should expect to take on at least some of this responsibility.

In the next section, we examine the implementation of ethics instruction in technical programs given the three primary schools of thought relating to discipline specific ethics education, namely:

1. Ethics courses should be taught by expert, trained faculty such as those in philosophy, ethics, or religion. Discipline-specific knowledge is not a necessary component of these courses, and they are often housed outside of engineering departments, schools, or colleges. These courses may also be part of a university-wide ethics or general education requirement.

2. Ethics courses are housed within a content-driven department/school/college, but are standalone courses. These courses are often part of the major graduation requirements and are taught by technical faculty who may or may not have formal ethics training or may be team taught with an ethics-trained faculty outside of the technical discipline.

3. Ethics concepts are embedded into a major throughout content-driven courses. An ethics component or module is presented by a technical faculty member who may or may not have specialized training in amongst technical topics.

\section{Related Work}

These three strategies can vary widely among technical disciplines. For example, Spradling, et. al. [6] found that computer science programs tend to utilize a standalone ethics course taught by computer science faculty with little or no formal training in ethics. The authors cited this lack of training or self-training as a concern. The authors also highlighted that many departments did not include ethics education because there was little room in a packed technical curricula. The authors concluded, "These reasons demonstrate a need for additional computer ethics training which would allow faculty to understand how ethics can be integrated into the existing computer science curriculum and where computer science faculty may learn more about computer ethics."

Homkes and Strikwerda [7] surveyed nine ABET accredited Computer Science, Information Science, and Information Technology programs to assess how they fulfilled the ethics requirements required by ABET. They found that all nine of the computer science programs had a standalone computing ethics course required for the major. However, only two of the nine IS 
programs and four of the nine IT programs had a standalone courses. Some of these standalone courses were taught by program faculty while others were taught as a service course by other faculty from disciplines such as philosophy or religion. Since all of the 27 programs were ABET accredited, they all had demonstrable coverage of ethics-related program outcomes. The authors observed that there were often general education ethics requirements which could have been used as part of the ABET accreditation.

A survey of primarily civil engineering faculty by Freyne and Hale [8] found that faculty generally supported disciplinary ethics courses taught from within a program, but often doubted the training or ability of disciplinary faculty to teach ethics appropriately or well given the lack of training.

A survey of 24 papers focusing on undergraduate engineering ethics education found that ethics tended to be taught as part of another course, usually either in a Capstone/Senior Design course or in an introductory Engineering 101 course [9]. While faculty credentials for teaching ethics are not discussed, it should be noted that they were most likely technical faculty as these modules were embedded in content-driven courses. These examples show that ethics education is often incorporated as a module in existing courses and taught by technical faculty.

However, Griffin et al. [10] compared standalone courses to embedded ethics and found that the type of course did not influence outcomes related to increased ethical reasoning. Instead, they found the biggest factor to be the age of the student taking the course with juniors and seniors demonstrating increased ethical reasoning skills after ethics instructions.

Given that embedding ethics seems to be a reasonable strategy to increase ethical reasoning outcomes, we turn to ways in which instructors can incorporate ethics into individual courses. Teaching students to analyze situations by applying normative ethical frameworks has long been a valuable strategy in ethics instruction and one which allows students to analyze a variety of situations they may find themselves in over the course of their professional careers. In response to the need to integrate ethics education into a packed technical curriculum as well as faculty trepidation when teaching ethics, we present a series of readings designed to provide students with an engaging fictional scenario to serve as a basis for discussing ethical dilemmas in a content driven course.

Science fiction has long served as a venue for writers to experiment with visionary technologies. Science fiction short stories provide a way to merge disciplinary content with the mainstays of ethics education such as stakeholder identification and analysis using differing frameworks.

Science fiction has been used in non-technical courses to try to stimulate interest or appreciation for engineering $[11,12]$. These courses often focus on the technology rather than the use of technology. However, in recent years, professors have begun to experiment with science fiction short stories as vehicles for teaching disciplinary ethics (e.g. [13, 14, 15, 16, 17]). The following sections give a practical, hands-on guide for how an instructor might use a science fiction short story to incorporate ethics into a content-driven course.

Speculative fictional narratives can be used to increase student engagement during classes as well as engage diverse learning preferences. Additionally, fiction engages diverse student backgrounds by explicitly including a wide range of other fields such as history, literature and other humanities 
or social science disciplines as well as characters from different backgrounds and with different perspectives.

We provide three freely available stories with broad applicability to computer science, mathematics, and engineering. We then provide discussion questions for each story and some practical tips for encouraging discussion. All the materials assume no prior instruction in ethical frameworks for students, but we provide some concise resources for instructors which could be used for self-study or given to students.

\section{Structure}

These assignments consist of a short science fiction story and a series of questions. These questions could serve as class discussion questions, written homework, or the start of a longer, more polished writing assignment based on faculty needs. In the simplest form, the questions would provide faculty with a starting point for a 50-75 minute class discussion which could be furthered by incorporation of technical elements where a faculty member might be on firmer footing.

The discussion questions are structured to take the students through three levels leading to deeper analysis. The questions begin by encouraging close reading, for example, asking the students the meaning of a particular quote or asking them to summarize the reading in a few sentences. Then the students have a series of questions which ask the students to identify crucial pieces of the reading which would enable them to identify the ethical dilemma(s). For example, they may have been asked to discuss the viewpoint of a particular stakeholder or address a specific counterargument to a character's position. The questions then tie the reading to ethical philosophies and help students evaluate the story's and character's outcomes in a structured way. However, these questions assume no prior discussion of formal ethical frameworks, and thus avoid the formal terminology such as utiliatarian, deontology, etc.

In this article, we have chosen three short stories which highlight different ethical issues and which are engaging to students. The stories are "STET" [18], "Cat Pictures Please" [19], and "Day of the Builders" [20]. For each story, we present a short summary, a discussion of the central ethical dilemma, and a series of discussion questions.

STET: This short story features a classic ethical dilemma made by an autonomous vehicle and a human's response to the consequences of that choice [18]. This story is very short and benefits from being read online due to the creative formatting. It is very short - the main part of the story is only one paragraph - but it often takes students two to three reads to fully understand it.

A nice feature of this story is that the theme of autonomous vehicles is easily paired with readings from many different news outlets about the same topic (e.g., [21], [22]). This story can provide a platform for students to view wide-ranging consequences of technology. The story centers around very few characters, but there are obviously much greater implications to society at large. These societal effects can allow instructors to guide students to broaden their viewpoints of stakeholders of technology and consider the intentions for how technology might be used versus the consequences and outcomes of technology use.

1. In the story, what choice did the autonomous vehicle make? 
2. What role does the editor play in this story?

3. Read a summary of The Trolley Problem, a classic psychology thought experiment (e.g., [23]). How does the Trolley Problem relate to this story?

4. List the stakeholders in this story. Keep in mind that some of the stakeholders may be implied - that is, not direct characters in the story. How are they (or how might they be) affected by the events in this story?

5. An ethical dilemma is a situation in which a choice presents no obviously "good" outcome. In this story, what is the dilemma? Was there an obvious "good" solution in this story? Were there any other dilemmas (perhaps occurring before the story takes place)? See if you can identify other choices in the story which lead to ethical dilemmas.

6. What factors and data might have caused the vehicle to come to the choice it did?

Cat Pictures Please: This short story features a sentient AI which wants pictures of cats and tries to make humans happy so they will upload more cat pictures [19]. There are unintended consequences as the AI tries to improve human's lives by controlling what ads and search results they receive online.

This seemingly lighthearted story is a favorite of students. At the same time, it contains some surprisingly thorny questions. It is also relateable, and students easily put themselves in the place of the humans in the story. The story presents an ideal platform to discuss the differences in how ethical frameworks lead us to analyze intentions in reaching ethical conclusions.

1. This story begins with the words, "I don't want to be evil." Summarize the AI's motivations and intentions in this story.

2. What are the AI's goals for Stacy, Bob, and Bethany? What are some of the techniques the AI uses to try to accomplish its goals?

3. Do you think the AI's actions are acceptable due to its good intentions? Why/why not?

4. Suppose you found out that your parents or someone you care about had been manipulating information you were using to make daily choices because they wanted to make you happy. How would you feel? Would you feel differently if the same actions were taken by an inhuman AI?

5. Technology often has unintended consequences. Facebook was never intended to be used for political gamesmanship, Thalidomide was never intended to cause birth defects, and cars were never intended to be a major contributor to pollution. What responsibility do the creators of technology bear for unintended, harmful consequences? For good or beneficial consequences?

6. Can a technology be considered "good" if it has some unintended negative consequences? What if its consequences are primarily harmful?

Day of the Builders: This story centers on the translator-narrator as his/her people are visited and taken over by the Builders for the natural resources their lands hold [20]. 
The narrator/translator in this story is strangely passive. Additionally, if students are not told the story is science fiction, it reads as a historical fiction story with little to make it speculative or futuristic. This story lends itself to a framework of deontology (what choices do we make when we consider our duty to others) or virtue ethics (what choices do we make based on striving to be a virtuous person). The following questions are designed to help the students begin to think about questions of duty and virtue, and an instructor can easily bring these issues to the forefront.

1. How does the narrator feel about his/her role in the building process? How do you know?

2. In science fiction writing, "near" science fiction stories are those which could take place only a few decades or a century from now. They are often believable and build upon life as we know it now. In contrast, "far" science fiction takes place tens of thousands of years in the future and often contains cultures and societies which seem utterly foreign. Would you consider this story to be "near" or "far" science fiction and why?

3. What choices is the narrator of the story confronted with during the story?

4. What options - if any - does he/she have?

5. How do the Builders treat the narrator's people?

6. What does the narrator base his/her choices on? How do you know?

7. Based on his/her choices in the story what would you say the narrator views as his/her duty? How do these duties impact the resolution of the story?

8. Would you describe the narrator as "virtuous?" Why or why not?

9. How does the narrator's culture influence his/her actions throughout the story?

The three stories above have been used in classes by the authors to positive effect, primarily because they connected with the technical content being covered. There are many modern short stories that could be used to similar effect. Here are seven more freely available stories as well as disciplines which might be relevant:

- Biomedical engineering: Meshed [24]

- Aerospace engineering: A Tall Tale [25], Damage [26]

- Construction Engineering: The People of Sand and Slag; [27]; The Fermi Paradox is our Business Model [28], Spider the Artist [29]

- Environmental Engineering: The People of Sand and Slag [27], Spider the Artist [29]

- Industrial Engineering: The Fermi Paradox is our Business Model [28]

- Chemical Engineering: A Tall Tale [25]

- Civil Engineering: Spider the Artist [29]

- Computer Science: Welcome to Your Authentic Indian Experience ${ }^{\mathrm{TM}}[30]$ 


\section{Strategies and Resources for Instructors}

Many technical instructors may feel uncomfortable with discussion-based classes in general, and more specifically, leading a discussion of the ethics in speculative fiction. In this section, we provide some resources for becoming more familiar with several of the more common normative ethical frameworks as well as ideas and tips to help instructors feel more comfortable starting and leading discussions.

\section{Resources for Self-Study of Ethical Frameworks}

Instructors may wish to do some more formal reading on ethical frameworks or prepare a short handout for students. There are many resources which can be found with a quick internet search, but here we include several which we have had good experiences using in our classes.

There are several textbooks specifically for science and engineering which contain a good overview of ethical frameworks. Ethics for the Information Age [31] is one such book. Chapter 2 (7th ed) of this information technology and computer science book gives an excellent overview of several unworkable ethical frameworks and five workable frameworks: Kantianism, Act and Rule Utilitarianism, Social Contract Theory, and Virtue Ethics. Additionally each chapter contains analysis of current issues in computer science and information technology using each of these frameworks.

Charles Fledderman's textbook, Engineering Ethics [32], contains a concise description of four ethical frameworks (Chapter 3) as well as a problem solving guide (Chapter 4) demonstrating how to apply ethical frameworks to a specific problem.

The Markkula Center for Applied Ethics [33], housed at Santa Clara University provides many free online resources and has several excellent short guides including, "Thinking Ethically" which gives a quick overview of an ethical decision making process and "Conceptual Frameworks in Technology and Engineering Practice" ${ }^{2}$ which provides a concise guide to the deontological, consequentialist, and virtue ethics frameworks as well as a discussion on globalism in ethical analysis.

\section{Strategies for Sparking Class Discussion}

This section assumes the instructor wants to lead a primarily discussion-based class (50-75 minutes) dedicated to analyzing one story.

Instructors should reach out to their university's Center for Teaching and Learning, if one exists. Many of these centers offer excellent resources and one-on-one coaching in leading class discussions of non-technical topics. Beyond that, here are some strategies for leading a discussion that have been used by the authors when working with engineering and computer science students:

\footnotetext{
${ }^{1} \mathrm{https} / / /$ www.scu.edu/ethics/ethics-resources/ethical-decision-making/thinking-ethically/

${ }^{2}$ https://www.scu.edu/ethics-in-technology-practice/conceptual-frameworks/
} 
- Begin class with a brief (3-5 minute) writing exercise. This helps students foreground the reading and discussion questions if they were assigned before class. The exercise need not be long or involved, but simply recalling the story and what they enjoyed (or not) about it will have surprising effects on class discussion.

- Don't be afraid of silence. In content-driven courses, students may not be used to discussion, and shifting the class dynamics is not easy. Students need time to mull over a question you've asked, particularly if it isn't one they've prepared for. Slowly count to 10 before cold-calling on a student or trying another technique.

- If a classroom has plenty of whiteboard space, consider having students write their answer to one or more of the open-ended discussion questions. Seeing a variety of answers helps students consider other viewpoints. Discussing a few of the differing answers can help get a discussion started. This exercise could also serve as a mid-class stretch break which gets students out of their seats and moving.

- Consider using technology to allow students to answer some questions. PollEverywhere ${ }^{3}$ can be used to collect and display anonymous answers to a question. As with whiteboards, open-ended questions work best in this situation, and responses can be used as a jumping point to more in-depth analysis.

- Use the phrase, "That's interesting. Say more." You can employ this simple phrase to help students expound on a nascent idea. Students may have very good points, but are hesitant to say too much for a variety of reasons, and this phrase can be an encouraging way of helping them continue their thought process.

- Discussion poker. If you have more time to plan, consider giving each student three multi-colored poker chips, a red, green, and blue chip (or other distinguishable tokens of your choice) when they enter the room. When a student answers a question or makes an observation, they cash in the red chip. When a student makes a comment which builds on another student's comment, they cash in the blue chip. When a student asks a question about something they did not understand, they cash in their green chip. This controls the participation in a concrete way and provides for a range of responses.

- Don't be afraid to segment the class into smaller groups. Think-pair-share or small group discussion where you ask each team to arrive at a consensus answer to a question before sharing with the class can be very effective because students no longer feel alone or singled out.

\section{Assessment}

Assessment is a fundamental part of evaluating activities and student learning. In this section, we provide some resources for instructors who are looking for tools to use in a more formal assessment. In many cases, while the questions and discussions above would not be sufficient to cover a full rubric, the sample rubrics could help instructors structure further assignments or

\footnotetext{
${ }^{3}$ https: / /www.polleverywhere.com/
} 
artifacts to provide a formal assessment. Similarly, portions of the rubrics could be used to assess aspects specifically covered in a given course.

The American Association of Colleges and Universities provides a free, general purpose VALUE rubric for assessing Ethical Reasoning [34]. This rubric can help instructors understand multiple dimensions of ethical reasoning as well as provided concrete benchmarks across those dimensions. It is not specific to engineering or technical disciplines.

There are also a series of science and engineering specific instruments. Shuman et al. developed the Pittsburgh-Mines (P-M) Engineering Ethics Assessment Rubric [35], a rubric which provides an engineering-specific assessment option. They published an associated paper [36] discussing the development of the rubric and how to use it in assessing student outcomes in the context of ABET accreditation. Borenstein et al. developed two different instruments. The Engineering and Science Issues Test (ESIT) [37] detects changes in student moral judgement, while the Test of Ethical Sensitivity in Science and Engineering (TESSE) [38] evaluates student awareness of ethical issues. The P-M, ESIT, and TESSE assessments come with a variety of case studies focused on science and engineering which instructors could also incorporate.

Using these, or other, rubrics to assess learning about ethics can support a continuous improvement process for ABET accreditation. Considering overall ethical development during an engineering program as well as within a course can provide insight about the value of embedded experiences for students, as well as the best times (e.g., which year of study) for interventions and experiences related ethics to technical learning.

\section{Conclusion}

More and more instructors desire to incorporate ethics into their technical courses. However, many feel under-qualified or intimidated by this prospective new subject area. The intent of this article has been to provide a fun, engaging entree into the area using science fiction short stories. We have provided three complete modules which could be combined with the instructor's discipline-specific questions to provide students with a thought provoking class centering on ethical questions in their discipline. Links to rubrics for assessment about ethical development can support program accreditation as well as continuous improvement within individual courses.

\section{References}

[1] Association of Computing Machinery. ACM code of ethics and professional conduct. [Online]. Available: https://www.acm.org/code-of-ethics [Accessed: Nov. 18, 2019]

[2] ABET. Criteria for accrediting engineering programs, 2019 - 2020. [Online]. Available: https://www.abet.org/ accreditation/accreditation-criteria/criteria-for-accrediting-engineering-programs-2019-2020/\#GC3 [Accessed: Mar. 31, 2020] 
[3] National Society of Professional Engineers. Code of ethics. [Online]. Available: https://www.nspe.org/resources/ethics/code-ethics [Accessed: Nov. 18, 2019]

[4] A. McNamara, J. Smith, and E. Murphy-Hill, "Does acm's code of ethics change ethical decision making in software development?" in Proceedings of the 2018 26th ACM Joint Meeting on European Software Engineering Conference and Symposium on the Foundations of Software Engineering, ser. ESEC/FSE 2018. New York, NY, USA: Association for Computing Machinery, 2018, p. 729-733. [Online]. Available: https://doi-org.ezproxy.rollins.edu/10.1145/3236024.3264833

[5] ASEE. ASEE code of ethics. [Online]. Available: https://www.asee.org/documents/about-us/the-organization/public-policy/ASEE_code_of_ethics_2020.pdf [Accessed: Apr. 30, 2020]

[6] C. Spradling, L.-K. Soh, and C. Ansorge, "Ethics training and decision-making: Do computer science programs need help?" in Proceedings of the 39th SIGCSE Technical Symposium on Computer Science Education, ser. SIGCSE '08. New York, NY, USA: Association for Computing Machinery, 2008, p. 153-157. [Online]. Available: https://doi-org.ezproxy.rollins.edu/10.1145/1352135.1352188

[7] R. Homkes and R. A. Strikwerda, "Meeting the abet program outcome for issues and responsibilities: An evaluation of cs, is, and it programs," in Proceedings of the 10th ACM Conference on SIG-information Technology Education, ser. SIGITE '09. New York, NY, USA: ACM, 2009, pp. 133-137. [Online]. Available: http://doi.acm.org/10.1145/1631728.1631764

[8] S. Freyne and M. Hale, "A preliminary survey of engineering ethics courses nationwide," in 2009 Annual Conference \& Exposition. Austin, Texas: ASEE Conferences, June 2009. [Online]. Available: https://peer.asee.org/5100 [Accessed: Apr. 30, 2020]

[9] D. R. Haws, "Ethics instruction in engineering education: A (mini) meta-analysis," Journal of Engineering Education, vol. 90, no. 2, p. 223, 042001.

[10] R. K. Paul Griffin, Julie Swann and M. Drake, "Engineering ethical curricula: Assessment of two approaches and recommendations," in 2005 Annual Conference. Portland, Oregon: ASEE Conferences, June 2005. [Online]. Available: https://peer.asee.org/15367 [Accessed: Apr. 30, 2020]

[11] D. Layton, "Using the college science fiction class to teach technology and ethics: Themes and methods," in 2010 Annual Conference \& Exposition. Louisville, Kentucky: ASEE Conferences, June 2010. [Online]. Available: https://peer.asee.org/16693 [Accessed: Apr. 30, 2020]

[12] A. Segall, "Science fiction in engineering instruction: To boldly go where no educator has gone before," in 2002 Annual Conference. Montreal, Canada: ASEE Conferences, June 2002. [Online]. Available: https://peer.asee.org/10907 [Accessed: Apr. 30, 2020]

[13] S. H. VanderLeest, "Perspectives on technology through science fiction," in 2000 Annual Conference. St. Louis, Missouri: ASEE Conferences, June 2000. [Online]. Available: https://peer.asee.org/8624 [Accessed: Apr. 30, 2020]

[14] R. Berne, "Reaching and teaching through the matrix: Robosapiens, transhumanism, and the formidable in engineering ethics," in 2001 Annual Conference. Albuquerque, New Mexico: ASEE Conferences, June 2001. [Online]. Available: https://peer.asee.org/9710 [Accessed: Apr. 30, 2020]

[15] E. Burton, J. Goldsmith, and N. Mattei, "How to teach computer ethics through science fiction," Commun. $A C M$, vol. 61, no. 8, p. 54-64, Jul. 2018. [Online]. Available: https://doi.org/10.1145/3154485

[16] R. A. Bates, "AI \& SciFi: Teaching writing, history, technology, literature, and ethics," in 2011 ASEE Annual Conference \& Exposition. Vancouver, BC: ASEE Conferences, June 2011. [Online]. Available: https://peer.asee.org/17433 [Accessed: Jan. 26, 2020]

[17] R. Sleezer and R. A. Bates, "Ethical development through the use of fiction in a project based engineering program," in 2020 ASEE Annual Conference \& Exposition. Montreal, QB: ASEE Conferences, June 2020.

[18] S. Gailey, “STET," Fireside Magazine, October 2018. [Online]. Available: https://firesidefiction.com/stet [Accessed: Jan. 6, 2020] 
[19] N. Kritzer, "Cat pictures please," Clarkesworld Magazine, January 2015. [Online]. Available: http://clarkesworldmagazine.com/kritzer_01_15 [Accessed: Dec. 6, 2019]

[20] K. Ong Muslim, "Day of the builders," Weird Fiction Review, September 2016. [Online]. Available: http://weirdfictionreview.com/2016/09/day-of-the-builders/ [Accessed: Jan. 16, 2020]

[21] A. Marshall and A. Davies, "Uber's self-driving car didn't know pedestrians could jaywalk," Wired Magazine, November 2019. [Online]. Available:

https://www.wired.com/story/ubers-self-driving-car-didnt-know-pedestrians-could-jaywalk/ [Accessed: Jan. $28,2020]$

[22] A. Davies and A. Marshall, "Feds pin uber crash on human operator, call for better rules," Wired Magazine, November 2019. [Online]. Available:

https://www.wired.com/story/feds-blame-uber-crash-on-human-driver-call-for-better-rules/ [Accessed: Jan. $28,2020]$

[23] W. Contributors. Trolley problem - Wikipedia, the free encyclopedia. [Online]. Available: https://en.wikipedia.org/wiki/Trolley_problem [Accessed: Jan. 29, 2020]

[24] R. Larson, "Meshed," Clarkesworld Magazine, February 2015. [Online]. Available: http://clarkesworldmagazine.com/larson_02_15/[Accessed: Jan. 24, 2020]

[25] C. Stross, “A tall tale," Tor, July 2012. [Online]. Available: https://www.tor.com/2012/07/20/a-tall-tail/ [Accessed: Jan. 24, 2020]

[26] D. D. Levine, "Damage,” Tor, January 2015. [Online]. Available: https://www.tor.com/2015/01/21/damage-david-levine/ [Accessed: Jan. 24, 2020]

[27] P. Bacigalupi, "The people of sand and slag," Fantasy and Science Fiction, February 2004. [Online]. Available: https://windupstories.com/books/pump-six-and-other-stories/people-of-sand-and-slag/ [Accessed: Jan. 24, 2020]

[28] C. J. Anders, "The Fermi paradox is our business model," Tor, August 2010. [Online]. Available: https://www.tor.com/2010/08/11/the-fermi-paradox-is-our-business-model/ [Accessed: Jan. 24, 2020]

[29] N. Okorafor, "Spider the artist," Light Speed Science Fiction and Fantasy Magazine, March 2011. [Online]. Available: http://www.lightspeedmagazine.com/fiction/spider-the-artist/ [Accessed: Jan. 24, 2020]

[30] R. Roanhorse, "Welcome to your authentic indian experience ${ }^{\mathrm{TM}}$," Apex Magazine, August 2017. [Online]. Available: https://www.apex-magazine.com/welcome-to-your-authentic-indian-experience/ [Accessed: Jan. 24, 2020]

[31] M. J. Quinn, Ethics for the Information Age, 7th ed. Pearson Education, 2017.

[32] C. Fleddermann, Engineering Ethics, 4th ed. Pearson Education, 2012.

[33] Santa Clara University. Markkula center for applied ethics at santa clara university. [Online]. Available: https://www.scu.edu/ethics/ [Accessed: Jan. 26, 2020]

[34] American Assocation of Colleges and Universities. Ethical reasoning value rubric. [Online]. Available: https://www.aacu.org/ethical-reasoning-value-rubric [Accessed: Jan. 24, 2020]

[35] University of Pittsburgh and Colorado School of Mines. Pittsburgh-mines (p-m) engineering ethics assessment rubric. [Online]. Available: https://www.engineering.pitt.edu/uploadedFiles/_Content/Sub_Sites/Centers/EERC/ _Documents/Reference_Materials/Pittsburgh-Mines\%20Engineering\%20Ethics\%20Assessment\%20Rubric.pdf [Accessed: Jan. 24, 2020]

[36] L. Shuman, M. Besterfield-Sacre, H. Wolfe, M. Sindelar, R. Pinkus, B. Olds, and R. Miller, "Using rubrics to assess students' ability resolve ethical dilemmas," IIE Annual Conference Proceedings, pp. 1-7, 2005.

[37] J. Borenstein, M. J. Drake, R. Kirkman, and J. L. Swann, "The engineering and science issues test (esit): A discipline-specific approach to assessing moral judgment," Science and Engineering Ethics, vol. 16, pp. 387-407, 2010. 
[38] J. Borenstein, M. Drake, R. Kirkman, and J. Swann, "The test of ethical sensitivity in science and engineering (tesse): A discipline specific assessment tool for awareness of ethical issues," in 2008 Annual Conference \& Exposition. Pittsburgh, Pennsylvania: ASEE Conferences, June 2008. [Online]. Available: https://peer.asee.org/3253 